\title{
Job Burnout of Contractual Workers in Nueva Ecija
}

\author{
Kim Edward S. Santos, Crisanto D. De Jesus \\ College of Management and Business Technology, Atate Campus, Nueva Ecija University of Science and Technology, Nueva Ecija, \\ Philippines \\ Email:kimnyte@gmail.com, kesantos@neust.edu.ph,crisddejsus@gmail.com
}

How to cite this paper: Santos, K.E.S. and De Jesus, C.D. (2020) Job Burnout of Contractual Workers in Nueva Ecija. Open Access Library Journal, 7: e6113. https://doi.org/10.4236/oalib.1106113

Received: January 28, 2020

Accepted: February 16, 2020

Published: February 19, 2020

Copyright (C) 2020 by author(s) and Open Access Library Inc.

This work is licensed under the Creative Commons Attribution International License (CC BY 4.0).

http://creativecommons.org/licenses/by/4.0/

\begin{abstract}
Job burnout is an uncomfortable and unhealthy disorder that would like to improve for both individuals and organizations. Descriptive method and Pearson moment correlation were used in this research. A total of 89 contractual workers (that are 9 months up to 6 years in service) employed in the malls of $\mathrm{Nu}$ eva Ecija were involved in this study. They were composed 50 males and 39 females whose ages range from 19 to 48 years old. Symptoms of Burnout were categorized into four such as physical, emotional exhaustion, reduced work performance, and work alienation from workmates. Based on the results of the study, the researchers concluded that physical and emotional exhaustion were the common symptoms that manifest when the contractual workers are burnout. Contractual workers have average degree level of burnout based on the combined four different symptoms such as physical, emotional exhaustion, reduced work performance, and alienation from workmates. Age of contractual workers can contribute to the higher tendency for them to experience physical and alienation from workmates as symptoms of burnout. Likewise, Years in service as contractual workers add to the higher possibility of experiencing emotional exhaustion and higher degree level of total burnout. In lieu of the foregoing conclusions, the researchers would like to recommend that an organization should implement self-care program for the contractual workers experiencing burnout. Furthermore, clear organization's guidelines and policies are implemented to let contractual workers stay motivated to work even they are experiencing burnout.
\end{abstract}

\section{Subject Areas}

Human Resource Management, Management Organization, Psychology, Sociology

\section{Keywords}

Burnout, Contractual Workers, Temporary Workers, Job Burnout 


\section{Introduction}

Job burnout is an uncomfortable and unhealthy disorder that would like to improve for both individuals and organizations. Job Burnout is a psychological condition involving a sustained on-the-job reaction to persistent interpersonal stressors [1]. Further, burnout represents the endpoint of a three-dimensional continuum of energy, involvement, and effectiveness Therefore, its opposite end is commitment to work, characterized by feeling motivated, engaged in one's work, and effective [2].

Job burnout appears to remove people from social interactions that are often aloof and unavailable to the very people they are supposed to be supporting [3]. Job satisfaction and job burnout show closely related behavior, inversely, when work burnout presents low scores, frustration is rising [4].

Burnout symptoms do not occur spontaneously but are derived from a personal and subjective view of one's life and what drives one's actions [5]. The source of burnout is often the point of the potential value of multifactorial interventions in structural work environment factors [6].

In light of the foregoing insights, the researchers would like to assess the level of burnouts of contractual workers and the relationship of demographics to this job burnout.

\section{Conceptual Framework}

Job burnout is characterized by symptoms of emotional exhaustion (e.g. feeling emotionally drained by work, feeling used up at the end of the day), depersonalization (e.g. feeling more callous towards other people, feeling emotionally hardened), as well as a decreased sense of personal accomplishment [7].

Workers demonstrate an undeniable awareness with regard to exposure to these effects, such that they associate a diverse set of health problems with the job: those that derive from the material working conditions as well as problems of a nervous, emotional and psychological nature [8].

Further, the cumulative risk estimate showed greater psychological distress among temporary employees compared with permanent employees [9]. What is desirable, though, is an attempt on the part of a company to regularly keep burnout under control through an advanced structured plan, and to intervene as necessary through certain preventive methods [10].

Researches have shown that burnout is present in the workplace. However, its symptoms and manifestations differ from one organization to another. Likewise, a link to some personal factors of the workers is somehow missing. With that, this research investigated what job burnout symptoms and its manifestations were present among contractual workers. Further, the researchers considered the relationship of contractual workers' age, sex and the length of their service to the overall leveling of their burnout.

\section{Objectives of the Study}

This paper aims to determine the signs of burnout among contractual workers as to Physical, Emotional Exhaustion, Reduced Work Performance and Alienation 
from Workmates. It also aims to determine the level of the contractual worker's burnout and the relationship of age, sex, and years in service of contractual workers to their level of burnout.

\section{Methodology}

The study used descriptive method as it describes the present condition. Descriptive research involves defining the characteristics of a particular occurrence based on an empirical analysis, or investigating the association between two or more phenomena [11]. A total 89 contractual workers (that are 9 months up to 6 years in service) employed in the malls of Nueva Ecija were involved in this study. They were composed 50 males and 39 females whose age ranges from 19 to 48 years old. The researchers utilized Likert-scale type questionnaire [12] and utilized descriptive statistical analysis like mean and weighted mean. Symptoms of Burnout were categorized into four such as physical, emotional exhaustion, reduced work performance, and work alienation from workmates.

Pearson moment correlation was used to determine the significant relationships among the variables [13].

\section{Results and Discussion}

Table 1 shows the different symptoms of burnout as experienced by the contractual workers as to physical, emotional exhaustion, reduced work performance, and alienation from workmates.

1) Physical Symptoms. Result shows that contractual workers had experienced physical symptoms of burnout with a weighted mean of 3.83 and verbal interpretation as "often". The physical symptoms of burnout which were very often experienced are "having problems in sleeping" $(\mathrm{X}=4.39)$, "more tired lately" $(\mathrm{X}=$ 4.28 ), and "have allergy flare ups or an increase in frequency of headaches" ( $\mathrm{X}=$ 4.25). Contractual workers also sometimes experienced other physical symptoms such as "sex drive has decreased" ( $\mathrm{X}=2.89)$, "have no time for grooming himself herself" ( $\mathrm{X}=2.78)$, and "aware of an increase in minor illness" $(\mathrm{X}=2.70)$.

2) Emotional Exhaustion. It was found out that contractual workers often experienced emotional exhaustion as symptoms of burnout as this got a mean of 3.67. Contractual workers "feel restless and difficult to concentrate" which has mean of 4.52 and a verbal interpretation of "very often". Other emotional exhaustions symptoms were "seriously question the worth of my efforts" $(X=2.98)$ and "find it increasingly difficult to make decisions" $(\mathrm{X}=2.67)$, which both statements have a verbal interpretation of "sometimes".

3) Reduced Work Performance. Generally, contractual workers sometimes experienced reduced work performance as symptoms of burnout with a weighted mean of 3.37. These symptoms are "think about my job during work hours" $(\mathrm{X}=$ 3.11), "feel bored about my work" ( $\mathrm{X}=2.67)$, and "work harder and accomplish less" ( $\mathrm{X}=2.71)$. However, there was a symptom that very often experienced by the contractual workers in terms of reduced work performance and that is " $d o$ the minimal amount of work necessary" $(\mathrm{X}=4.35)$. 
Table 1. Symptoms of burnout as experienced by the contractual workers.

\begin{tabular}{|c|c|c|}
\hline Physical & Mean & VI \\
\hline 1) I am more tired lately. & 4.28 & $\mathrm{VO}$ \\
\hline 2) I have allergy flare ups or an increase in frequency of headaches. & 4.25 & $\mathrm{VO}$ \\
\hline 3) My physical appearance is sloppy and disheveled. & 4.10 & $\mathrm{O}$ \\
\hline 4) I am aware of an increase in minor illness. & 2.70 & $S$ \\
\hline 5) My sex drive has decreased. & 2.89 & $\mathrm{~S}$ \\
\hline 6) I am having problems sleeping. & 4.39 & $\mathrm{VO}$ \\
\hline 7) I have no time for grooming myself. & 2.61 & $\mathrm{R}$ \\
\hline 8) I have problem overeating/undereating. & 2.78 & $\mathrm{~S}$ \\
\hline Weighted mean & 3.84 & O (Often) \\
\hline Emotional Exhaustion & Mean & VI \\
\hline 1) I am more irritable and less patient. & 3.71 & $\mathrm{O}$ \\
\hline 2) I find it increasingly difficult to make decisions. & 2.67 & $S$ \\
\hline 3) I feel restless and difficult to concentrate. & 4.52 & $\mathrm{VO}$ \\
\hline 4) I lose control of emotions more easily. & 3.89 & $\mathrm{O}$ \\
\hline 5) I worry about little things. & 3.96 & $\mathrm{O}$ \\
\hline 6) I am constantly depressed. & 3.65 & $\mathrm{O}$ \\
\hline 7) I seriously question the worth of my efforts. & 2.98 & $S$ \\
\hline 8) I focus more on the problems than on the positives. & 4.03 & $\mathrm{O}$ \\
\hline Weighted Mean & 3.67 & O (Often) \\
\hline Reduced Work Performance & Mean & VI \\
\hline 1) I easily forget my appointments, commitment or valuables. & 3.75 & $\mathrm{O}$ \\
\hline 2) I work harder and accomplish less. & 2.71 & S \\
\hline 3) I procrastinate doing work that is important. & 3.59 & $\mathrm{O}$ \\
\hline 4) I do the minimal amount of work necessary. & 4.35 & $\mathrm{VO}$ \\
\hline 5) I look forward to do nothing. & 3.87 & $\mathrm{O}$ \\
\hline 6) I think about my job during work hours. & 3.11 & S \\
\hline 7) I am spending more time doing unnecessary things rather that doing my work. & 2.65 & S \\
\hline 8) I feel bored about my work. & 2.98 & $\mathrm{~S}$ \\
\hline Weighted Mean & 3.37 & (S) Sometimes \\
\hline Alienation with Workmates & Mean & VI \\
\hline 1) I distance myself from people with whom I work. & 2.25 & $\mathbf{R}$ \\
\hline 2) I think I can do the job better than anyone else. & 3.50 & O \\
\hline 3) I believe others don't appreciate me. & 2.04 & $\mathbf{R}$ \\
\hline 4) I want to be left alone. & 4.03 & $\mathrm{O}$ \\
\hline 5) I find it difficult to accept responsibility from others. & 3.50 & O \\
\hline 6) I become bored when working with others. & 2.75 & $S$ \\
\hline 7) I believe we do not equal contributions to our work. & 1.53 & $\mathbf{N}$ \\
\hline 8) I blame others for my mistake. & 2.88 & $S$ \\
\hline Weighted Mean & 2.81 & Sometimes \\
\hline \multicolumn{3}{|l|}{ Legend: } \\
\hline Weighted Mean (WM) & Verbal Interpretation $(V I)$ & \\
\hline $4.24-5.00$ & Very Often (VO) & \\
\hline $3.43-4.23$ & Often $(\mathrm{O})$ & \\
\hline $2.62-3.42$ & Sometimes (S) & \\
\hline $1.81-2.61$ & Rarely (R) & \\
\hline $1.00-1.80$ & Never $(\mathrm{N})$ & \\
\hline
\end{tabular}


4) Alienation from Workmates. Based on the result, contractual workers scored a mean of 2.81 with a verbal description of "sometimes" in the alienation from workmates symptoms of burnout. Manifestations of these symptoms were "want to be left alone" ( $\mathrm{X}=4.03)$, "think hel she can do the job better than anyone else" $(\mathrm{X}=3.50)$, "find it difficult to accept responsibility from others" $(\mathrm{X}=3.50)$. On the other hand, contractual workers never experienced "believe they do not equal contributions to our work" ( $\mathrm{X}=1.53)$ as alienation from workmates symptom of burnout.

The results imply that manifestations of each symptom of burnout vary on the experience of contractual workers.

Table 2 shows the summary of symptoms and level of burnout among contractual workers. Overall, contractual workers got a weighted mean of 3.42 in the symptoms of burnout which has a verbal interpretation of "sometimes" and considered as "average level".

Based from the results, physical $(\mathrm{X}=3.84)$ and emotional exhaustion $(\mathrm{X}=$ 3.67) were the symptoms of burnout that contractual workers often experienced. And these symptoms were found to be of high level. On the other hand, reduced work performance and alienation from workmates were symptoms of burnout that they sometimes experienced and found to be of an average level. The results may imply that the common manifestation when contractual workers were burnout can be easily noticed through physical and emotional exhaustion symptoms.

Table 3 presents the relationship of age, sex, and years in service to the symptoms of and level of burnout among contractual worker. Based on the result, it was found out that age is positively and significant to physical $(r=0.297, \mathrm{p}<$ $0.01)$ and alienation from workmates $(r=0.270, p<0.01)$. This illustrates that as a contractual worker gets older the higher the tendency he/she will experience physical symptoms of burnout. That is a contractual worker will get more tired, has sleeping problems, and increase in frequency of headaches. On the other hand,

Table 2. Summary of symptoms and level of burnout among contractual workers.

\begin{tabular}{|c|c|c|c|}
\hline Symptoms & Mean & Verbal Description & Level \\
\hline 1) Physical & 3.84 & Often & High \\
\hline 2) Emotional Exhaustion & 3.67 & Often & High \\
\hline 3) Reduced Work Performance & 3.37 & Sometimes & Average \\
\hline 4) Alienation from workmates & 2.81 & Sometimes & Average \\
\hline Weighted Mean & 3.42 & Sometimes & Average \\
\hline \multicolumn{4}{|l|}{ Legend: } \\
\hline Weighted Mean (WM) & \multicolumn{2}{|c|}{ Verbal Interpretation ( VI) } & Level \\
\hline $4.24-5.00$ & \multicolumn{2}{|c|}{ Very Often (VO) } & Very High \\
\hline $3.43-4.23$ & \multicolumn{2}{|c|}{ Often $(\mathrm{O})$} & High \\
\hline $2.62-3.42$ & \multicolumn{2}{|c|}{ Sometimes (S) } & Average \\
\hline $1.81-2.61$ & \multicolumn{2}{|c|}{ Rarely (R) } & Low \\
\hline $1.00-1.80$ & \multicolumn{2}{|c|}{ Never (N) } & Very Low \\
\hline
\end{tabular}


Table 3. Relationship of age, sex, and years in service to the symptoms and level of burnout among contractual workers.

\begin{tabular}{cccccc}
\hline Variables & Physical & $\begin{array}{c}\text { Emotional } \\
\text { Exhaustion }\end{array}$ & $\begin{array}{c}\text { Reduced } \\
\text { Work } \\
\text { Performance }\end{array}$ & $\begin{array}{c}\text { Alienation } \\
\text { from } \\
\text { Workmates }\end{array}$ & $\begin{array}{c}\text { Total } \\
\text { Level of } \\
\text { Burnout }\end{array}$ \\
\hline Age & $\mathbf{0 . 2 9 7 ^ { * }}$ & 0.264 & -0.257 & $\mathbf{0 . 2 7 0 ^ { * }}$ & 0.236 \\
Sex & 0.116 & -0.037 & -0.108 & 0.106 & -0.122 \\
Years in Service & 0.238 & $\mathbf{0 . 3 8 5 ^ { * * }}$ & 0.246 & 0.307 & $\mathbf{0 . 3 6 5 ^ { * * }}$ \\
\hline
\end{tabular}

${ }^{*}$ Significant $\mathrm{p}<0.01 ;{ }^{*}$ Significant $\mathrm{p}<0.05$.

younger contractual workers have lower tendency to experience these kinds of symptoms. Moreover, older contractual workers may have the higher tendency to experience alienation from workmates as symptoms of burnout. This means that as the contractual workers get older they may experience to distance themselves from others because of their negative thoughts towards them. Younger contractual workers have lower tendency to experience these alienation from workmates symptoms of burnout.

Furthermore, it was also found out that years in service of contractual workers are positively and significantly related to emotional exhaustion symptoms $(r=$ $0.385, p<0.05)$ and to the total level of burnout $(r=0.365, p<0.05)$. These results may imply that the longer you stay as contractual worker the higher the possibility that you will experience emotional exhaustion symptoms of burnout that is you will experience the feeling restless and difficult to concentrate and, likewise, will get higher tendency to suffer burnout. It is in contradicted to those who are new contractual workers as they have the lower possibility to experience emotional exhaustion.

Sex of the contractual workers was found out not related to any symptoms of burnout.

\section{Conclusions and Recommendations}

Based on the results of the study, the researchers concluded that physical and emotional exhaustion were the common symptoms that manifest when the contractual workers are burnout. Contractual workers have average degree level of burnout based on the combined four different symptoms such as physical, emotional exhaustion, reduced work performance, and alienation from workmates. Age of contractual workers can contribute to the higher tendency for them to experience physical and alienation from workmates as symptoms of burnout. Likewise, Years in service as contractual workers add to the higher possibility of experiencing emotional exhaustion and higher degree level of total burnout.

In lieu of the foregoing conclusions, the researchers would like to recommend that an organization should implement self-care program for the contractual workers experiencing burnout. Furthermore, clear organization's guidelines and policies are implemented to let contractual workers stay motivated to work even they are experiencing burnout. 


\section{Conflicts of Interest}

The authors declare no conflicts of interest regarding the publication of this paper.

\section{References}

[1] Rossi, A.M., Perrewé, P.L. and Sauter, S.L. (2006) Stress and Quality of Working Life: Current Perspectives in Occupational Health. IAP.

[2] Leiter, M.P. and Maslach, C. (2005) 36 A Mediation Model of Job Burnout. Research Companion to Organizational Health Psychology. 544.

https://doi.org/10.4337/9781845423308.00046

[3] Potter, B.A. (2009) Overcoming Job Burnout: How to Renew Enthusiasm for Work. Ronin Publishing, Berkeley, CA.

[4] Sobreques, J., Cebria, J., Segura, J., Rodriguez, C., Garcia, M. and Juncosa, S. (2003) Job Satisfaction and Burnout in General Practitioners. Atencion Primaria, 31, 227-233. https://doi.org/10.1016/S0212-6567(03)79164-1

[5] Längle, A. (2003) Burnout-Existential Meaning and Possibilities of Prevention. European Psychotherapy, 4, 107-121.

[6] Aronsson, G., Theorell, T., Grape, T., Hammarström, A., Hogstedt, C., Marteinsdottir, I. and Hall, C. (2017) A Systematic Review Including Meta-Analysis of Work environment and Burnout Symptoms. BMC Public Health, 17, Article Number: 264. https://doi.org/10.1186/s12889-017-4153-7

[7] Morgan 3rd, C.A., Cho, T., Hazlett, G., Coric, V. and Morgan, J. (2002) The Impact of Burnout on Human Physiology and on Operational Performance: A Prospective Study of Soldiers Enrolled in the Combat Diver Qualification Course. The Yale Journal of Biology and Medicine, 75, 199-205.

[8] Castanheira, F. and Chambel, M.J. (2009) Emotion Work, Psychological Contract, and Their Relationship with Burnout. New Research Trends in Effectiveness, Health, and Work: A Criteos Scientific and Professional Account. 101-120.

[9] Virtanen, M., Kivimäki, M., Joensuu, M., Virtanen, P., Elovainio, M. and Vahtera, J. (2005) Temporary Employment and Health: A Review. International Journal of Epidemiology, 34, 610-622. https://doi.org/10.1093/ije/dyi024

[10] Beheshtifar, M. and Omidvar, A.R. (2013) Causes to Create Job Burnout in Organizations. International Journal of Academic Research in Business and Social Sciences, 3, 107-113.

[11] Creswell, J.W. and Creswell, J.D. (2017) Research Design: Qualitative, Quantitative, and Mixed Methods Approaches. Sage Publications, Thousand Oaks, CA.

[12] Vagias, W.M. (2006) Likert-Type Scale Response Anchors. Clemson International Institute for Tourism and Research Development, Department of Parks, Recreation and Tourism Management. Clemson University, Clemson.

[13] Mukaka, M.M. (2012) A Guide to Appropriate Use of Correlation Coefficient in Medical Research. Malawi Medical Journal, 24, 69-71. 